(Final Mar '04.1)

\title{
Lighting for the Human Circadian Clock.
}

\section{Recent Research Indicates That Lighting Has \\ Become a Public Health Issue.}

\author{
Stephen M. Pauley MD FACS
}

PO Box 3759

Ketchum, Idaho 83340

For reprints contact Dr. Pauley: spauley@cox-internet.com 


\section{Abstract}

The hypothesis that the suppression of melatonin (MLT) by exposure to light at night (LAN) may be one reason for the higher rates of breast and colorectal cancers in the developed world deserves more attention. The literature supports raising this subject for awareness as a growing public health issue. Evidence now exists that indirectly links exposures to LAN to human breast and colorectal cancers in shift workers. The hypothesis begs an even larger question: has medical science overlooked the suppression of MLT by LAN as a contributor to the overall incidence of cancer?

The indirect linkage of breast cancer to LAN is further supported by laboratory rat experiments by David E. Blask and colleagues. Experiments involved the implanting of human MCF-7 breast cancer cell xenografts into the groins of rats and measurements were made of cancer cell growth rates, the uptake of Linoleic Acid (LA), and MLT levels. One group of implanted rats were placed in light-dark (12L: 12D) and a second group in light-light (12L:12L) environments. Constant light suppressed MLT, increased cancer cell growth rates, and increased LA uptake into cancer cells. The opposite was seen in the light-dark group. The proposed mechanism is the suppression of nocturnal MLT by exposure to LAN and subsequent lack of protection by MLT on cancer cell receptor sites which allows the uptake of LA which in turn enhances the growth of cancer cells.

MLT is a protective, oncostatic hormone and strong antioxidant having evolved in all plants and animals over the millennia. In vertebrates, MLT is normally produced by the pineal gland during the early morning hours of darkness, even in nocturnal animals, and is suppressed by exposure to LAN.

Daily entrainment of the human circadian clock is important for good human health. These studies suggest that the proper use and color of indoor and outdoor lighting is important to the health of both 
humans and ecosystems. Lighting fixtures should be designed to minimize interference with normal circadian rhythms in plants and animals.

New discoveries on blue-light-sensitive retinal ganglion cell light receptors that control the circadian clock and how those receptors relate to today's modern high intensity discharge (HID) lamps are discussed. There is a brief discussion of circadian rhythms and light pollution. With the precautionary principle in mind, practical suggestions are offered for better indoor and outdoor lighting practices designed to safeguard human health.

\section{Summary}

Studies now indirectly link exposures of shift workers to LAN and higher incidences of breast cancer and colorectal cancers. One possible mechanism is MLT suppression by shift worker eye exposures to LAN. The pineal gland hormone MLT is normally produced at highest levels in the early morning hours, but is suppressed by open eye exposure to LAN. Rat studies by David E. Blask and colleagues show that MLT acts as a protective oncostatic agent that suppresses growth rates of human MCF-7 breast cancer cell xenografts. MLT likely offers similar protections in humans. The minimum amount of white light required to increase growth rates of implanted cancer cells in rats is as little as 0.2 lux, twice the illuminance of a full moon.

The role of the eye's influence on circadian rhythms and pineal MLT production is discussed. David E. Berson's discovery of specialized, blue light sensitive retinal ganglion cells that connect to the human clock center is important since commonly used modern outdoor high intensity discharge (HID) lamps like metal halide (MH), mercury vapor (MV), high pressure sodium (HPS), and fluorescent lamps all contain blue wavelengths. 
Because of its ability to inhibit MLT production, light itself acts like a drug. Exposure of opened human eyes to LAN in the early morning hours and the subsequent lowering of human MLT levels may explain the increased incidence of certain cancers in the developed world. Therefore, this hypothesis introduces LAN as a public health issue. The type, intensity, and color of indoor and outdoor lighting must be carefully considered. Practical day and night time lighting suggestions are offered.

\section{Light and the Evolution of the Circadian Clock}

Since we are born into a world of artificial lighting, we don't give much thought to how light disrupts the normal 24 hour circadian rhythms present in all organisms. Biological clock rhythms are found in all living things, even in organisms as simple as algae (59-61). Clock genes that time cellular functions were likely inherited from the earth's first simple organisms over four billion years ago. The circadian clock is dependent upon dark nights that allow normal MLT production between 2:00 A.M. and 4:00 A.M., and bright daylight that entrains or re-sets the clock to begin a new 24 hour day. These systems are exquisitely sensitive to light-dark cycles, and in mammals the system is triggered by photons of light striking specialized cells in the eye's retina $(6-8,17,21)$.

Homo sapiens evolved from primates, who for millions of years timed their body clocks to a rising Sun and a dark night. Five hundred thousand years ago our ancestors, Homo erectus, learned to warm and light the cold darkness by the dim flickering flames of an orange-red fire. Edison's electric light has been with us since 1879 , merely an instant in evolutionary time. It is only since Edison and our ability to work around the clock that we have disrupted this system through the use of artificial night lighting. 
Early incandescent lamps were dim and their yellow light did not significantly affect circadian mechanisms. Recent technological advances in lighting have made nighttime lights more efficient but also far brighter. Today's lights emit more blue wavelengths than the early gas, kerosene, and incandescent lamps. Medical research indicates that blue light is very effective in reducing naturally occurring human MLT levels $(14,19)$.

\section{Light Pollution}

Light pollution is produced by the use of ever brighter outdoor night lighting that is often used for the advertising of gas stations, convenience stores, and shopping centers. It is often justified in the name of "security." Since the 1960's we have seen the increased outdoor use of HID lamps.

Light pollution is light that is not targeted for a specific task, is bright and uncomfortable to the human eye, causes unsafe glare to drivers and pedestrians, harms the biological integrity of ecosystems, causes light to trespass into homes and bedrooms, and creates skyglow above cities. Skyglow obliterates our views of the stars and planets. It also wastes energy by shining non targeted light upward into space.

Light pollution has been recognized as both a quality of life and an environmental issue for years (www.darksky.org), but only recently has the use of light at night attracted the attention of health researchers $(1,9,11,27,30,40,69,70-75)$. We know now that artificial light acts like a drug in its ability to disrupt the biological clocks of living organisms. Light receptors in the eye that send electric impulses directly to the biological clock were only recently discovered (6-8).

\section{Receptor Cell Discovery}

In year 2002, Brown University neuroscientist David M. Berson discovered a previously unknown function for retinal ganglion cells (RGC) (7). Previously unknown connections and functions of a 
small population of RGC located in the base of the retina of rats were identified. Berson demonstrated that RGC axons connect to the circadian or biological clock center - the paired suprachiasmatic nuclei $(\mathrm{SCN})$ - located within the hypothalamus at the base of the brain. The retinal circadian light transmission system is also coupled to the visual system of rods (scotopic vision) and cones (photopic vision).

Most sensitive to blue light (464-484 nanometers), RGC control the human circadian clock, a complex biological system that, through light perception, tells our bodies how to regulate multiple body functions such as body temperature, the release of hormones from the pituitary gland, sleep patterns, and our production of MLT from the pineal gland $(5,20,47,60,61)$.

Berson's discovery is a major contribution to the basic understanding of how circadian clock systems work and is recognized as a major advancement in the field of circadian research.

\section{Blue Light Photopigment}

Melanopsin, a blue light sensitive photopigment, resides within the small population of RGC (42, 49). The RGC are located deep in the retina of the eye beneath the rods and cones. These specialized cells are non-visual photoreceptors previously thought to only relay to the brain nerve impulses initiated by light striking the rods and cones. The RGC and their dendrites fire maximally when stimulated by blue light at wavelengths between 464 and 484 nanometers (7). By comparison, the visual system of the rods and cones fire maximally at $507 \mathrm{~nm}$ (green) and $555 \mathrm{~nm}$ (green-yellow) respectively.

A year before Berson's discovery, George C. Brainard found that human MLT levels were reduced most when volunteers with dilated pupils were exposed for ninety minutes between the hours of 2:00 AM and 3:30 A.M. to monochromatic blue light at 464 nanometers and at an illuminance of just 0.1 
lux, equivalent to the light of a full moon $(14,19)$. Brainard proposed a "novel" non-visual photoreceptor that is separate from the rods and cones, later identified as melanopsin $(16,42)$.

\section{Light at Night, Shift Workers, Breast Cancer and Colorectal Cancer}

Because much of the daytime work force in the industrialized world is exposed to dim office lighting instead of bright sunlight, and because at night we are often exposed to bright lights with blue wavelengths instead of natural darkness, some researchers believe that adequate human circadian entrainment does not take place $(58,74)$. Without a normal cycle of MLT inhibition and production responding to cycles of light and dark, human health may be negatively affected $(5,22,29,38,47$, $54,57,60,61,76)$.

Shift workers and breast cancer: Recent epidemiological studies of night shift worker populations show higher rates of breast cancer ranging from thirty six to sixty percent $(27,41,69,70,73-75)$ Richard G. Stevens noted that breast cancer rates are three to five times lower in the developing world than in the industrialized world. About 40,000 women die each year from breast cancer, and the cause of fifty percent of the breast cancers in the US is unknown. The electric light is the hallmark of modern life in the industrialized world and could possibly be linked to the higher rates of breast cancer (75). Further research is needed on MLT amplitude measurements in shift workers and a correlation of those data with the incidences of cancers in shift workers $(32,40)$.

Shift workers and colorectal cancer: Eva S. Schernhammer et al, reviewed data from the Harvard Nurses' Health Study of 78,586 women, the same prospective study group that she found had higher rates of breast cancer among night shift workers. The authors found a higher incidence of colorectal cancer as high as thirty five percent among shift workers who worked a rotating night shift at least three nights per month for fifteen or more years (71). 
In addition, totally blind people with no light perception to interfere with MLT production have lower incidences of breast cancer than blind people with at least some light perception $(24,35,39$, $46,55,78)$.

Adding to these data is the observation that breast cancer rates are lower in the developing world where there are far lower nighttime lighting levels than in the industrialized world which has excessively bright levels of nighttime lighting $(69,73,75)$.

\section{Melatonin and Human Breast Cancer Cell Growth}

Melatonin regulates and protects: MLT is a hormone that has sleep-inducing properties and regulates a balanced physiological state in humans (59-61). MLT also has substantial free radical scavenging/antioxidant and anticancer activity in experimental systems $(45,60,61,63)$. This knowledge has obvious relevance to human health $(22,26,54,60,61,66,79)$.

The production and suppression of MLT is a circadian driven event. MLT is synthesized by the pineal gland, a pea sized gland located in the center of the brain. MLT is normally produced in darkness with highest levels occurring between 2:00 and 4:00 A.M., and is suppressed by the interruption of darkness by artificial LAN.

Dim light suppresses MLT and enhances tumor growths. Early rat studies by Blask, Sauer \& colleagues showed that exposures to LAN (12L:12L) reduced nocturnal MLT levels and increased the growth rates of implanted rat liver cancer (hepatoma) tumors $(65,67,68)$. Even dim light suppresses MLT. MLT suppression was seen using only 0.2 lux of white light. Rats kept in a 
normal day-night cycle (12L:12D) showed high MLT levels at night, and much slower hepatoma cell growth rates. Similar increased hepatoma growth rates were seen whether white light was presented at 300 lux, a typical illumination level for office buildings, or at 0.2 lux., twice the light of a full moon (9-13). This reveals a highly sensitive retinal-circadian system in rats. Humans exhibit highly sensitive responses to low levels of blue light. Brainard's human experiments revealed MLT suppression by exposure to 90 minutes of only 0.1 lux of $464 \mathrm{~nm}$ blue light, equal to the illumination from a full moon $(14,19)$.

Human breast cancer cell implants in rats: When darkness was interrupted by 300 lux of constant white LAN (12L:12L), rats with implanted human MCF-7 breast cancer xenografts had lower nocturnal MLT levels, the cancers took up significantly more LA, and grew faster than rats kept in a normal day- night environment (12L:12D). In both animal experiments, adding MLT slowed cancer cell growth by seventy percent and reduced LA uptake indicating that MLT has oncostatic properties $(9-13)$.

Possible mechanism: Over $90 \%$ of human ductal carcinomas and over $80 \%$ of normal human breast tissue have MLT receptor sites (28). The protection that MLT provides to inhibit human breast cancer cell growth rates in rats may be due to the ability of MLT to attach to such receptor sites. The supposition is that the attachment of MLT prevents the uptake and tumor nourishment by LA which in turn inhibits cancer cell growth (9).

Do bright lights and fatty diets harm human health? The hypothesis is that early morning eye exposure to ordinary illumination levels of light containing blue wavelengths suppresses MLT and combined with the consumption of food high in fat (LA) leads to higher rates of breast and colorectal cancers. Additional studies also connect lowered MLT levels to breast and colon cancers 
$(1,2,3,30-34)$. The collective research cited here does suggest such an association. The inappropriate use of LAN should be given serious consideration as a cause for today's high rates of breast and colorectal cancers in the industrialized world.

\section{How Much, How Long, and What Color?}

MLT suppression by LAN will depend on the color of the light, its intensity, and the duration of the exposure of the eyes (both opened and closed) to the light source. A study by T. Hatonen et al. found that only two of eight human subjects exposed to 2000 lux of white light for 60 minutes with eyes closed between midnight and 2:00 AM showed lowered MLT levels. The authors doubt that people sleeping with eyes closed in urban environments would have suppression of MLT (43). Typical room illuminations range from $150-180$ lux. However, not all people sleep soundly and many awaken during the night with open eyes in bedrooms bathed with light from television sets, computer screens, reading lights, or light from outdoor streetlights coming into unshaded bedroom windows. Studies are needed to document MLT levels in fitful sleepers exposed to varying levels of bedroom illumination.

More research is also needed to determine the exact illumination levels and durations of exposure to the various colored light sources required to suppress human MLT. A theoretical model was reported by Karl Schulmeister et al. (72). Using the action spectrum of MLT, calculations were done showing some possible threshold lighting levels and associated time durations at which human MLT would be suppressed by fifty percent.

Results showed that monochromatic red light at 100 lux, a reasonable living room lighting level, would take four hundred and three hours of exposure to suppress MLT by fifty percent; a candle - 
sixty-six minutes; a sixty watt incandescent bulb - thirty-nine minutes; a fifty-eight watt deluxe daylight fluorescent light - fifteen minutes; and a pure white high-output LED - thirteen minutes.

The authors comment that since the 1960's lighting technology has progressed from the incandescent bulb (yellow light) to today's HID lamps. Street lights like the amber colored HPS lights, white colored MH lights, blue-green colored MV lights, and white colored, high output fluorescent lights, expose humans to more and more blue light wavelengths than in earlier times.

Blue light emissions suppress melatonin the most: Brainard showed in human experiments that even very dim (0.1 lux) blue light suppresses MLT more than other colors. Therefore, open eye exposure to light sources at night containing blue light (HID and fluorescent lamps have blue emissions) may pose a potential health risk to humans. New light meters must be designed to detect light affecting the human circadian system and used in conjunction with standard visual (photopic) light meters.

S.W. Lockley et al. found that humans exposed to 6.5 hours of monochromatic blue light (460 $\mathrm{nm}$ ) caused a) a two fold greater circadian phase delay with $460 \mathrm{~nm}$ light than with $555 \mathrm{~nm}$ (photopic) light; b) MLT was suppressed twice as much with $460 \mathrm{~nm}$ light than with $555 \mathrm{~nm}$ light (48). The study confirms that human pineal MLT production and suppression is primarily blue wavelength dependent and separate from the photopic (cone) visual system. 


\section{The "Precautionary Principle"}

The implications of these findings are that perhaps the "precautionary principle" should be applied in lighting applications. Carlin wrote:

"The precautionary principle is no longer just a theory. Writing in Scientific American, David Appell notes how the precautionary principle is increasingly finding its way into international agreements. He noted for example, that while it is already 'a matter of law in Germany and Sweden, the precautionary principle may soon guide the policy of all of Europe (24).' ",

Writing in Rachel's Environment \& Health Weekly, editor Peter Montague states that "scientific uncertainty should be cause for caution, not for plunging ahead recklessly...better safe than sorry. That is the philosophy of precaution (51)."

An international gathering of scientists, government officials, lawyers, labor groups, and grassroots environmental activists, met January 23-25, 1998 at Wingspread in Racine, Wisconsin to define and discuss the precautionary principle. Part of their concluding statement reads:

"When an activity raises threats of harm to human health or the environment, precautionary measures should be taken even if some cause and effect relationships are not fully established scientifically. In this context the proponent of an activity, rather than the public, should bear the burden of proof (24)."

While no definite cause and effect can now be made between light, circadian disruption, and cancers in humans, evidence is mounting that says there is such linkage. Like the early years of the tobacco and lung cancer debates, warnings and public awareness programs regarding the use of day and nighttime lighting may be warranted. Specifically, artificial day and night lighting systems should be designed and re-designed to enhance rather than disrupt this very sensitive and visually separate retinal-circadian system which is separate from the visual system. 


\section{Better Lighting Practices Should Begin Now}

Until more research directly links exposure to LAN to increased rates of human cancers, it may be wise to consider preventive measures in the application of everyday lighting practices.

The best way to daily entrain (reset) our circadian clocks and have our bodies produce a healthy dose of Vitamin D is to get fifteen minutes of natural sunlight exposure each morning (43). At night we should sleep in total darkness. But in modern industrialized societies we see people with poor sleep habits. There are a growing number of people working both day and night shift jobs. Studies have shown that shift workers will phase-shift their circadian rhythms (56). Disruption of normal nighttime MLT secretory rhythms due to shift work is likely harmful to human physiology.

Biologically friendly lighting: The two basic goals are a) to entrain the circadian clock during daylight through the use of bright, full spectrum white light, and b) at night to use non-glare, nonblue outdoor and indoor lights $(50,53,58,64)$. Daytime office lighting in buildings without windows is often so dim that it is unable to entrain the circadian clock to suppress MLT, and therefore one is exposed to a "biological darkness" (74). The best office daytime lighting source should be from natural daylight. Where windows in office spaces are not possible, non-glare, bright, full-spectrum white light should be used so as to entrain the circadian clock to daytime.

Indoor lighting: Indoor nighttime lighting should be dim, eliminate wavelengths in the blue, and employ lights with wavelengths shifted toward the yellow and orange. Reading by incandescent lights rather than fluorescent lights will reduce exposure to blue color emissions. Complete darkness during sleep is preferred. Televisions should not be left on during sleeping hours. Blinds should be closed if light from street lighting or flood lighting enters bedroom windows. 
Street lighting: Residential street lighting should employ fully shielded (“full cutoff”) light to eliminate or at least minimize light trespass into homes. The preferred high intensity discharge (HID) light source is high pressure sodium (HPS) because of its high efficiency and long bulb life. HPS also has lower amplitudes of blue light emission. Metal halide (MH) and mercury vapor (MV) are less efficient and emit higher amplitudes of blue light. Low pressure sodium (LPS) lights have the advantage of being the most efficient i.e. LPS emits the most lumens per watt of all the commonly used outdoor light sources. LPS emits a single wavelength of yellow light (589 nm), and is therefore least likely to lower human melatonin levels. LPS is also preferred by astronomers since it is easily filtered making the imaging of celestial objects less difficult. A disadvantage of LPS is its yellow color which is not popular with the public, law enforcement, or emergency personnel. The very poor color rendering index (CRI) for LPS results in red objects appearing as black. However, the use of full cutoff LPS residential street lights may prove to be friendlier to circadian rhythms than the typical HPS, MH, MV drop-lens, cutoff and semi cutoff HID lamps which emit blue wavelengths.

Graveyard shift lighting: Lighting for graveyard shift workers should approximate daytime lighting, but only if the shift worker sleeps in total darkness (wearing a sleep mask) during the day, thereby phase shifting the circadian clock to a different day-night cycle. Using the precautionary principle, shift workers should be advised that preliminary studies now indicate that there are health risks associated with work performed in the early morning hours, and that the risk of breast and colorectal cancer increases as the number of days of shift work increase.

Nursing home lighting: Elderly patients should be exposed to natural sunlight via skylights and other daytime lighting techniques. Where windows and skylights are not possible, bright, non-glare 
white light should be available in daytime ranging from 2500 to 3000 lux $(37,50,53,64,77)$. At night, the use of red lights to light the way to bathrooms will minimize MLT suppression. A small nursing home pilot study by Figueiro indicates that Alzheimer's patients exposed to closely approximated blue lights during afternoon daylight hours may entrain the circadian clock, increase alertness, reduce afternoon patient agitation (“sundowning”) and promote better sleep at night (36).

\section{Conclusion}

Lighting only for visual acuity or to achieve decorative effects is no longer acceptable (58). Lighting must also be friendly to the circadian clock. We must recognize the body's need to sleep in darkness which allows for the normal night time production of MLT . MLT is a long-evolved protective hormone that should be allowed full expression during early morning hours.

On the basis of the growing body of animal research and human epidemiological studies the hypothesis that exposure to LAN may in certain circumstances harm human health should receive more attention. More research is needed before one can definitively state that LAN harms human health. But with the knowledge of the newly identified separate blue light-sensitive, retinalcircadian system, the indirect epidemiological evidence that LAN exposure to shift workers may contribute to breast and colorectal cancers, and Blask's and colleagues' rat-LAN-MLT- human breast and liver cancer cell research, mounting evidence suggests precautions should now be taken with the design and application of both indoor and outdoor lighting.

Stephen M Pauley MD FACS

4070 words; 79 refs.

PO Box 3759

Ketchum, Idaho $\quad$ spauley@cox-internet.com $\quad$ Final March 2004 (Mar '04.12) 


\section{References}

1. Anisimov V.N., Hansen J.

Light, endocrine systems and cancer - a meeting report.

Neuroendocrinol Lett. 2002; Jul;23 Suppl 2:84-7.

2. Anisimov V.N., Popovich I.G., Zabezhinski M.A.

Melatonin and colon carcinogenesis: I. Inhibitory effect of melatonin on

development of intestinal tumors induced by 1,2-dimethylhydrazine in rats.

Carcinogenesis. 1997; 18: 1549-53

3. Anisimov V.N., Popovich I.G., Shtylik A.V., Zabezinski M.A., Fen-Huh H., Gurevich P., et al. Melatonin and colon carcinogenesis. III. Effect of melatonin on proliferative activity and apoptosis in colon mucosa and colon tumors induced by 1,2-dimethylhydrazine in rats.

Exp Toxic Pathol. 2000; 52: 71-6

4. Appell D.

The New Uncertainty Principle.

Scientific American. 2001; Jan.

5. Arendt J.

Melatonin, circadian rhythms, and sleep.

New England Journal of Medicine. 2000; Oct 12;343(15):1114-6.

6. Berson D.M.

Strange vision: ganglion cells as circadian photoreceptors.

Trends Neurosci. 2003; Jun; 26(6):314-20

7. Berson D.M., Dunn F.A., Motoharu T.

Phototransduction by retinal ganglion cells that set the circadian clock.

Science. 2002; 295:1070-73 


\section{Berson D.M.}

Melanopsin and phototransduction by retinal ganglion cells.

Final Report. The Fifth International LRO Lighting Research Symposium, "Light and Human Health", November 3-5, 2002. Report No. 1009370. The Electric Power Research Institute, Palo Alto, CA. March, 2004.

9. Blask D.E., Dauchy R.T., Sauer L.A., Krause J.A., Brainard G.C.

Growth and fatty acid metabolism of human breast cancer (MCF-7) xenografts in nude rats: impact of constant light-induced nocturnal melatonin suppression.

Breast Cancer Res Treat. 2003; Jun;79(3):313-20.

10. Blask D.E., Sauer L.A., Dauchy R.T., Holowachuk E.W., Ruhoff M.S., Kopff H.S.

Melatonin inhibition of cancer growth in vivo involves suppression of tumor fatty acid metabolism via melatonin receptor-mediated signal transduction events.

Cancer Res. 1999; 59:4693-701

11. Blask D.E., Dauchy R.T., Sauer L.A., Krause J.A., Brainard G.C.

Light during darkness, melatonin suppression and cancer progression.

Neuroendocrinol Lett. 2002; Jul;23 Suppl 2:52-6.

12. Blask D.E., Wilson S.T., Cos S., Lemus-Wilson A.M., Liaw L.

Pineal and circadian influence on the inhibitory growth response of experimental breast cancer to melatonin.

Proc $74^{\text {th }}$ Annu Meet Endocr Soc. 1992:376

13. Blask D.E., Sauer L.A., Dauchy R.T.

Melatonin as a chronobiotic/anticancer agent: cellular, biochemical, and molecular mechanisms of action and their implications for circadian-based cancer therapy.

Curr Top Med Chem. 2002; Feb; 2(2):113-32 
14. Brainard G.C.

Photoreception for regulation of melatonin and the circadian system in humans.

Final Report. The Fifth International LRO Lighting Research Symposium, "Light and Human Health", November 3-5, 2002. Report No. 1009370. The Electric Power Research Institute, Palo Alto, CA. March, 2004.

15. Brainard G.C., Richardson B.A., Petterborg L.J., Reiter R.J.

The effect of different light intensities on pineal melatonin content.

Brain Res. 1982; Feb 4;233(1):75-81

16. Brainard G.C., Hanifin .J.P, Rollag M.D., Greeson J., Byrne B., Glickman G., et al. Human melatonin regulation is not mediated by the three cone photopic visual system.

J Clin Endocrinol Metab. 2001; Jan;86(1):433-6

17. Brainard G.C., Rollag M.D., Hanifin J.P.

Photic regulation of melatonin in humans: ocular and neural signal transduction. J Biol Rhythms. 1997; Dec;12(6):537-46

18. Brainard G.C., Lewy A.J., Menaker M., Fredrickson R.H., Miller L.S., Weleber R.G., et al. Dose-response relationship between light irradiance and the suppression of plasma melatonin in human volunteers.

Brain Res. 1988; Jun 28;454(1-2):212-8

19. Brainard G.C., Hanifin J.P., Greeson J.M., Byrne B., Glickman G., Gerner E. et al. Action spectrum for melatonin regulation in humans: evidence for a novel circadian photoreceptor.

J Neuroscience. 2001; 21 (16):6405-6412 
20. Brainard G.C.

Pineal research: the decade of transformation.

J Neural Transm Suppl. 1978;(13):3-10.

21. Brainard G.C., Richardson B.A., King T.S., Reiter R.J.

The influence of different light spectra on the suppression of pineal melatonin content in the Syrian hamster.

Brain Res. 1984; Mar 5;294(2):333-9

22. Bubenik G.A., Blask D.E., Brown G.M., Maestroni G.J., Pang S.F., Reiter R.J. et al.

Prospects of the clinical utilization of melatonin.

Biol signals and recept. 1998; Jul-Aug, 7(4):195-219)

23. Carlin S.

The Precautionary Principle.

http://www.preventionisthecure.org/preprin.html

Web site for Devra Davis $\mathrm{PhD}$

24. Coleman M.P., Reiter R.J.

Breast cancer, blindness and melatonin.

Eur J Cancer.1992;28(2-3):501-3. Review

25. Cos S., Sanchez-Barcelo E.J.

Melatonin and mammary pathological growth.

Front Neuroendocrinol. 2000; Apr;21(2):133-70.

26. Cos S., Sanchez-Barcelo E.J.

Melatonin, experimental basis for a possible application in breast cancer prevention and treatment.

Histol Histopathol. 2000; Apr;15(2):637-47. Review. 
27. Davis S., Mirick D.K., Stevens R.G.

Night-shift work, light at night, and risk of breast cancer.

J Natl Cancer Inst. 2001; 93:1557-62

28. Dillon D.C., Easley S.E., Asch B.B., Cheney R.T., Brydon L., Jockers R., et al.

Differential expression of high-affinity melatonin receptors (MT1) in normal and malignant human breast tissue.

Am J Clin Pathol. 2002; 118:451-458

29. Dollins A.B., Lynch H.J., Wurtman R.J., Deng M.H., Lieberman H.R.

Effects of illumination on human nocturnal serum melatonin levels and performance.

Physiol Behav. 1993; Jan;53(1):153-60

30. Erren T.C.

Does light cause internal cancers? The problem and challenge of an ubiquitous exposure.

Neuroendocrinol Lett. 2002; Jul;23 Suppl 2:61-70.

31. Erren T.C., Piekarski C.

Does winter darkness in the Artic protect against cancer? The melatonin hypothesis revisited. Med Hypotheses. 1999; Jul;53(1):1-5.

32. Erren T.C., Stevens R.G.

Light, melatonin and internal cancers - recent facts and research perspectives.

Gesundheitswesen. 2002; May;64(5):278-83. German.

33. Falkson G., Falkson H.C., Steyn M.E., Rapoport B.L., Meyer B.J.

Plasma melatonin in patients with breast cancer.

Oncology. 1990; 47(5):401-5.

34. Ferriol M., Venereo Y., Orta X., Castellanos J.M., Segovia-Selvestre T.

In vitro effects of melatonin on cell proliferation in a colon adenocarcinoma line.

J Appl Toxicol. 2000; 20: 21-4 
35. Feychting M., Osterlund B., Ahlbom A.

Reduced cancer incidence among the blind.

Epidemiology. 1998; Sep;9(5):490-4.

36. Figueiro M., Eggleston G., Rea M.S.

Effects of Light Exposure on Behavior of Alzheimer's Patients-a Pilot Study.

Final Report. The Fifth International LRO Lighting Research Symposium, "Light and Human Health", November 3-5, 2002. Report No. 1009370. The Electric Power Research Institute, Palo Alto, CA. March, 2004.

37. Fontoynont $\mathrm{M}$.

Simulation of Sunlight in Indoor Environments.

Final Report. The Fifth International LRO Lighting Research Symposium, "Light and Human Health", November 3-5, 2002. Report No. 1009370. The Electric Power Research Institute, Palo Alto, CA. March, 2004.

38. Glickman G., Levin R., Brainard G.C.

Ocular input for human melatonin regulation: relevance to breast cancer.

Neuroendocrinol Lett.; 2002 Jul 23 Suppl 2:17-22.

39. Hahn R.A.

Profound bilateral blindness and the incidence of breast cancer.

Epidemiology; 1991; 2:208-210

40. Hansen J.

Light at night, shiftwork, and breast cancer risk; editorial

J N Cancer Inst; 2001; 93:1513-15

41. Hansen J.

Increased breast cancer risk among women who work predominately at night.

Epidemiology. 2001; 12:74-7 
42. Hattar S., Lucas R.J., Mrosovsky N., Thopson S., Douglas R.H., Hankins M.W. et al. Melanopsin and rod-cone photoreceptive systems account for all accessory major visual functions in mice.

Nature. 2003; July 3; 424:75-81

43. Hatonen T., Alila-Johansson A., Mustanoja S., Laakso M.L.

Suppresson of Melatonin by 2000-lux Light in Humans with Closed Eyes.

Biol Psychiatry 1999; 46:827-831

44. Holick M.F.

Vitamin D: A Required Supplement or a Sunshine Hormone?

Final Report. The Fifth International LRO Lighting Research Symposium, "Light and Human Health", November 3-5, 2002. Report No. 1009370. The Electric Power Research Institute, Palo Alto, CA. March, 2004.

45. Karbownik M., Lewinski A., Reiter R.J.

Anticarcinogenic actions of melatonin which involve antioxidative processes: comparison with other antioxidants.

Int J Biochem Cell Biol. 2001; Aug; 33(8): 735-53

46. Kliukiene J., Tynes T., Andersen A.

Risk of breast cancer among Norwegian women with visual impairment.

Br J Cancer. 2001; Feb 2;84(3):397-9.

47. Lewy A.J., Wehr T.A., Goodwin F.K.

Light suppresses melatonin secretions in humans.

Science. 1980; 210:1267-1269 
48. Lockley S.W., Brainard G.C., Czeisler C.A.

High sensitivity of the human circadian melatonin rhythm to resetting by short wavelength light.

J Clin Endocrinol Metab. 2003; Sep; 88(9): 4502-05

49. Lucas R.J., Hattar S., Takao M., Berson D.M., Foster RG, Yau K.W.

Diminished pupillary light reflex at high irradiances in melanopsin knock out mice.

Science. 2003; Jan 10: 245-247

50. Miller N.

Lighting for Seniors: Obstacles in Applying the Research.

Final Report. The Fifth International LRO Lighting Research Symposium, "Light and Human Health", November 3-5, 2002. Report No. 1009370. The Electric Power Research Institute, Palo Alto, CA. March, 2004.

51. Montague $P$.

The Precautionary Principle

Rachel's Environment \& Health Weekly \#586

Feb. 19, 1998 http://www.monitor.net/rachel/r586.html

52. Nathan P.J., Burrows G.D., Norman T.R.

The effect of dim light on suppression of nocturnal melatonin in healthy women and men.

J Neural Transm 1997;104(6-7):643-8

Curr Top Med Chem. 2002 Feb;2(2):113-32.

53. Noell-Waggoner E.

Let There Be Light, or Face the Consequences: A National Concern for our Aging Population.

Final Report. The Fifth International LRO Lighting Research Symposium, "Light and Human Health", November 3-5, 2002. Report No. 1009370. The Electric Power Research Institute, Palo Alto, CA. March, 2004. 
54. Pang S.F., Pang C.S., Poon A.M, Lee P.P., Liu Z.M., Shiu SY.

Melatonin: a chemical photoperiodic signal with clinical significance in humans.

Chin Med J (Engl). 1998; Mar;111(3):197-203.

55. Pukkala E., Verkasalo P.K., Ojamo M., Rudanko S.L.

Visual impairment and cancer: a population-based cohort study in Finland.

Cancer Causes and Control. 1999; 10:13-20

56. Quera-Salva M.A., Defrance R., Claustrat B., De Lattre J., Guilleminault C.

Rapid shift in sleep time and acrophase of melatonin secretion in short shift work schedule.

Sleep. 1996; Sep;19(7):539-43.

57. Ramstad K., Loge J.H.

Melatonin treatment of a blind child with serious sleep disorders

Tidsskr Nor Laegeforen. 2002; Apr 20;122(10):1005-6. Norwegian.

58. Rea M.S.

Light- Much More Than Vision.

Keynote address

Final Report. The Fifth International LRO Lighting Research Symposium, "Light and Human Health", November 3-5, 2002. Report No. 1009370. The Electric Power Research Institute, Palo Alto, CA. March, 2004.

59. Rea M.S., Bullough J.D., Figueiro M.G.

Phototransduction for human melatonin suppression.

J Pineal Res. 2002; May;32(4):209-13.

60. Reiter R.J.

Melatonin

Bantam Books; 1995 
61. Reiter R.J.

Melatonin: clinical relevance.

Best Pract Res Clin Endocrinol Metab. 2003; Jun; 17(2): 273-85

62. Reiter R.J., Tan D.X., Burkhardt S., Manchester L.C.

Melatonin in plants.

Nutr Rev. 2001; Sep;59(9):286-90.

63. Reiter R.J., Tan D., Cabrera J., D’Arpa D.

Melatonin and tryptophan derivatives as free radical scavengers and antioxidants.

Adv Exp Med Biol. 1999; 467: 379-87

64. Roberts J.E.

Light Interactions with the Human Eye as a Function of Age.

Final Report. The Fifth International LRO Lighting Research Symposium, "Light and Human Health", November 3-5, 2002. Report No. 1009370. The Electric Power Research Institute, Palo Alto, CA. March, 2004.

65. Sauer L.A., Dauchy R.T., Blask D.E.

Melatonin inhibits fatty acid transport in inguinal fat pads of hepatoma 7288CTC-bearing and normal Buffalo rats via receptor-mediated signal transduction.

Life Sci. 2001; May 11; 68(25):2835-44.

66. Sauer L.A., Dauchy R.T., Blask D.E.

Polyunsaturated fatty acids, melatonin, and cancer prevention.

Biochemical Pharmacology. 2001; 61; 1455-1462

67. Sauer L.A., Dauchy R.T., Blask D.E.

Mechanism for the antitumor and anticachetic effects of n-3 fatty acids.

Cancer Res. 2000; 60 5289-9567. 
68. Sauer L.A., Dauchy R.T., Blask D.E., Armstrong B.J., Scalici S.

13-Hydroxyoctadecadienoic acid is the mitogenic signal for linoleic aciddependent growth in rat hepatoma $7288 \mathrm{CTC}$ in vivo.

Cancer Res. 1999; Sep 15;59(18):4688-92.

69. Schernhammer E.S., Schulmeister K.

Melatonin and cancer risk: does light at night compromise physiologic cancer protection by lowering serum melatonin levels?

Brit J Cancer. 2004; Mar 8; 90(5): 941-3

70. Schernhammer E.S., Laden F., Speizer F.E., Willett W.C., Hunter D.J., Kawachi I., et al. Rotating night shifts and risk of breast cancer in women participating in the Nurses' Health Study.

J Natl Cancer Inst. 2001; 93:1563-8

71. Schernhammer E.S., Laden F., Speizer F.E., Willett W.C., Hunter D.J., Kawachi I., et al. Night-Shift Work and Risk of Colorectal Cancer in the Nurses' Health Study. J Natl Cancer Inst. Vol.95, No.11, 825-828, June 4. 2003

72. Schulmeister K., Weber M., Bogner W., Schernhammer E.

Application of Melatonin Action Spectra on Practical Lighting Issues.

Final Report. The Fifth International LRO Lighting Research Symposium, "Light and Human Health", November 3-5, 2002. Report No. 1009370. The Electric Power Research Institute, Palo Alto, CA. March, 2004.

73. Stevens R.G.

Lighting during the day and night: Possible impact on risk of breast cancer. Neuroendocrinol Lett. 2002; Jul;23 Suppl 2:57-60 
74. Stevens R.G., Rae M.S.

Light in the Built Environment: Potential Role of Circadian Disruption in Endocrine

Disruption and Breast Cancer.

Cancer Causes and Control. 2001;12:279-287

75. Stevens R.G.

Epidemiological Evidence on Artificial Lighting Patterns and Risk of Breast Cancer.

Final Report. The Fifth International LRO Lighting Research Symposium,

"Light and Human Health", November 3-5, 2002. Report No. 1009370. The

Electric Power Research Institute, Palo Alto, CA. March, 2004.

76. Stewart K.T., Gaddy J.R., Byrne B., Miller S., Brainard G.C.

Effects of green or white light for treatment of seasonal depression.

Psychiatry Res. 1991; Sep;38(3):261-70.

77. Veitch J.A.

Principles of Healthy Lighting.

Final Report. The Fifth International LRO Lighting Research Symposium, "Light and Human Health", November 3-5, 2002. Report No. 1009370. The Electric Power Research Institute, Palo Alto, CA. March, 2004.

78. Verkasalo P.K., Pukkala E., Stevens R.G., Ojamo M., Rudanko S.L.

Inverse association between breast cancer incidence and degree of visual impairment in Finland.

Br J Cancer. 1999; Jul;80(9):1459-60.

79. Wiley T.S., Formby B.

Lights Out; Sleep, Sugar, and Survival

Pocket Books; 2000 


\section{Acknowledgements:}

I wish to acknowledge the Lighting Research Office (LRO), a service of the Electric Power Research Institute, Palo Alto, CA, for holding their meeting on Light and Human Health in Orlando, Fl, November 3-5, 2002. Neither the LRO nor the Electric Power Research Institute expressly endorses the ideas and content of this paper.

The Expedition Inspiration Fund for Breast Cancer Research and the late Laura Steele Evans who inspired thousands of breast cancer survivors were motivators for this paper.

The International Dark Sky Association, Bob Crelin, and Cliff Haas have been inspirational and informational sources in guiding my interests toward the development and passage of local outdoor lighting ordinances and the control and prevention of light pollution in Idaho. 